\title{
Lactobacillus sp. obtenidas de Tetragonisca angustula frente a Fusarium poae y Fusarium chlamydosporum
}

\author{
Lactobacillus sp. obtained from Tetragonisca angustula against \\ Fusarium poae and Fusarium chlamydosporum \\ María José Cabana1*, José José1, Ricardo Manuel Castro ${ }^{1}$, \\ Marcelo Benitez Ahrendts ${ }^{1}$
}

\section{RESUMEN}

Fusarium poae y Fusarium chlamydosporum, generadores de micotoxinas y causantes de la pudrición en raíces y tallos de plantas de importancia agrícola, son un gran problema mundial. Tetragonisca angustula, una abeja nativa sin aguijón, produce mieles con actividad antifúngica y antibacteriana. En este estudio se aisló y evaluó el efecto inhibidor de bacterias lácticas provenientes de mieles de esa especie de abeja frente a F. poae y F. chlamydosporum. Se obtuvieron 8 colonias de Lactobacillus sp. (LB1, LB2, LB3, LB4, LB5, LB6, LB7, LB8), las cuales presentaron diferentes comportamientos antagónicos frente a los hongos patógenos. La bacteria láctica LB4 mostró un efecto controlador total para ambos hongos y fue seleccionada como un futuro controlador biológico.

Palabras clave: bacterias ácido lácticas, inhibición, biocontrolador, hongos patógenos.

\section{ABSTRACT}

Fusarium poae and Fusarium chlamydosporum are mycotoxin generators, and the reason for root and stem rotting of agriculturally important plants; making them a major global problem. Tetragonisca angustula, a native stingless bee, produces kinds of honey with antifungal and antibacterial activity. In this study, the inhibitory effect of lactic bacteria from the honey of this bee species was isolated and evaluated against $\mathrm{F}$. poae and $\mathrm{F}$. chlamydosporum; where 8 colonies of Lactobacillus sp. (LB1, LB2, LB3, LB4, LB5, LB6, LB7, LB8) presented different antagonistic behaviors against pathogenic fungi. Lactic bacteria LB4 presenting a total controlling effect for both fungi, thus being selected as a future biological controller.

Keywords: lactic acid bacteria, inhibition, bio controller, pathogenic fungi.

\section{Introducción}

Fusarium sp. genera diferentes enzimas hidrolíticas, que degradan la pared celular y son importantes en la patogenicidad (Pekkarinen et al., 2003). Algunas especies de Fusarium sp. se caracterizan por producir toxinas en cereales como trigo, cebada, avena (Schwarz, 2003). F. Poae es un hongo que se asocia a la producción de micotoxinas y afecta tanto a los humanos como a los animales (Stenglein, 2009).

F. chlamydosporum es causante del tizón de pata de canguro (Anigozanthos ssp), del damping off en plantas de té y de la podredumbre del tallo de la ocra (Palmero et al., 2008). Genera la toxina
T-2 en el maíz blanco y otros tricotecenos del grupo A (Carrillo et al., 2001).

Una alternativa frente a estas enfermedades es la aplicación de bacterias lácticas, que generan productos bioactivos, proporcionando beneficios antimicrobianos (Aween et al., 2012).

Las bacterias ácido lácticas se caracterizan por ser Gram positivas, no esporuladas, anaeróbicas o facultativas aeróbicas, catalasa negativa. (Quinto et al., 2014). La microbiota de las colonias de las abejas presenta un gran reservorio de bacterias lácticas, empleadas para diversos propósitos (Ramos et al., 2019).

La abeja nativa sin aguijón, Tetragonisca angustula, se encuentra distribuida desde el sur

1 Universidad Nacional de Jujuy, Facultad de Ciencias Agrarias. Mendoza, Argentina.

*Autor por correspondencia: mariajosecabanv@gmail.com 
de México hasta Argentina (Yáñez-Ordóñez et al., 2008). La práctica de meliponicultura se lleva a cabo desde la época precolombina, y su miel es utilizada por sus propiedades etnofarmacológicas (Cortopassi et al., 2006). Trabajos recientes establecieron su acción antimicrobiana (Zamora et al., 2017).

Este trabajo tiene como objetivo aislar y evaluar el efecto inhibidor de bacterias lácticas provenientes de mieles de $T$. angustula frente a $F$. poae y $F$. chlamydosporum.

\section{Materiales y métodos}

\section{Obtención de muestra}

La muestra de miel se obtuvo del meliponario que se encuentra en las instalaciones de la Facultad de Ciencias Agrarias-Unju.

\section{Aislamiento de bacterias acido lácticas de la miel de melipona}

La muestra de miel se diluyó en 1:10 $\mathrm{ml}$ de agua peptonada y se incubó a $30^{\circ} \mathrm{C}$ por 24 horas. Transcurrido este periodo se sembró en caldo MRS a $37^{\circ} \mathrm{C}$ en microareofilia por $24 \mathrm{~h}$. Posteriormente se realizó el aislamiento en medio MRS sólido en las condiciones detalladas anteriormente. De todos los aislamientos se obtuvieron colonias de bacterias con características macroscópicas y microscópicas del género Lactobacillus sp. (Kandler et al., 1994).

\section{Selección de bacterias con efecto inhibitorio sobre Fusarium poae y Fusarium chlamydosporum}

$F$. poae y $F$. chlamydosporum se obtuvieron del cepario del laboratorio de Microbiología Agrícola, Facultad de Ciencias Agrarias-Unju.

Las colonias de lactobacilos seleccionadas se enfrentaron con las cepas de $F$. poae y F. chlamydosporum. Se agregaron $20 \mu \mathrm{l}$ de cultivo de bacterias ajustadas a una concentración de 1.6 $10^{9} \mathrm{UFC} / \mathrm{ml}$ en medio Agar Sabouraud, donde se sembró un explante de cada especie de hongo. Se realizaron cinco repeticiones de cada una de ellas. Se incubaron a $27^{\circ} \mathrm{C}$ por 7 días. Transcurrido este período se realizó la medición del crecimiento fúngico.

\section{Análisis estadístico}

Para el análisis de los resultados se empleó el programa INFOSTAD, aplicando un diseño complementario aleatorio, con comparación de medias con el test de Tuckey.

\section{Resultados}

Se seleccionaron 8 colonias fenotípicas correspondientes al género Lactobacillus sp., identificadas como LB1, LB2, LB3, LB4, LB5, LB6, LB7, LB8. Se registraron los promedios de crecimiento de los controles de $F$. poae y $F$. chlamydosporum, y de las inhibiciones generadas por las bacterias lácticas (Tabla 1).

Tabla 1. Promedios del efecto inhibitorio de las bacterias lácticas obtenidas de la miel de $T$. angustula frente a las colonias de $F$. poae y $F$. chlamydosporum.

\begin{tabular}{ccc}
\hline Muestras & $\begin{array}{c}\text { Promedio de crecimiento } \\
\text { de colonias de F. poae }(\mathrm{mm})\end{array}$ & $\begin{array}{c}\text { Promedio crecimiento de colonias } \\
\text { de } F . \text { chlamydosporum }(\mathrm{mm})\end{array}$ \\
\hline Testigo & $86 \pm 0,77$ & $85,74 \pm 0,68$ \\
\hline LB1 & $83,9 \pm 1,38$ & $83,44 \pm 0,68$ \\
\hline LB2 & $26,84 \pm 1,34$ & $23,52 \pm 0,58$ \\
\hline LB3 & $22,08 \pm 0,85$ & $18,62 \pm 0,98$ \\
\hline LB4 & 0 & 0 \\
\hline LB5 & $26,82 \pm 1,10$ & $25,64 \pm 0,61$ \\
\hline LB6 & $23,94 \pm 1,31$ & $23,58 \pm 0,54$ \\
\hline LB7 & $23,86 \pm 0,57$ & $23,98 \pm 0,45$ \\
\hline LB8 & $20,78 \pm 1,13$ & $17,58 \pm 2,64$ \\
\hline
\end{tabular}


En el efecto inhibidor se destacaron las cepas LB3, LB4, LB6 y LB7, LB8 para $F$. poae y LB3, LB4 y LB8, contra $F$. chlamydosporum.

Al realizar el análisis estadístico se obtuvo una diferencia significativa con un $\mathrm{p}$ valor $<0,0001$ entre los tratamientos y los hongos patógenos. Para F. poae, el análisis estadístico de las medias mostró que no se presentaron diferencias significativas del efecto inhibidor entre las cepas LB7 y LB6 y entre LB5 y LB2, que redujeron el crecimiento del hongo, observándose presencia de conidios. Se evidenciaron diferencias significativas entre las medias de las cepas LB3, LB4 y LB8, las cuales mostraron mejor efecto antagónico. Sin embargo, el mayor poder inhibitorio lo presentó la cepa LB4, con un control total sobre del hongo (Figura 1).

En lo que respecta a $F$. chlamydosporum, el análisis estadístico de las medias de las diversas bacterias lácticas no registró diferencias significativas entre las cepas LB7, LB6, LB5, LB2 y entre LB8 y LB3, que lograron detener el crecimiento del hongo, pero mostraron desarrollo de conidios. Se destacó LB4, con un efecto antagónico total sobre el hongo Figura 2).

\section{Discusión}

Las pruebas de inhibiciones realizadas con las diferentes colonias de bacterias lácticas mostraron en su mayoría efecto antagónico frente a las cepas de hongos patógenos. Esto concuerda con lo expuesto por Schillinger et al., 2010, quienes expresaron que las bacterias lácticas presentaron la capacidad de inhibir el crecimiento de diversos hongos toxicogénicos.

El análisis estadístico de las medias de las bacterias lácticas mostró igualdad en el efecto antagónico de algunas de ellas y diferencias entre otras, lo cual se relacionó con la presencia de metabolitos secundarios que contenía cada una de las colonias bacterianas. Se vinculó la inhibición a los compuestos que presentaron las bacterias como moléculas de bajo peso molecular, donde se encontró ácido orgánico, reuterina, peróxido de hidrógeno, ácidos grasos, y compuestos fenólicos, entre otros (Bartkiene et al.,

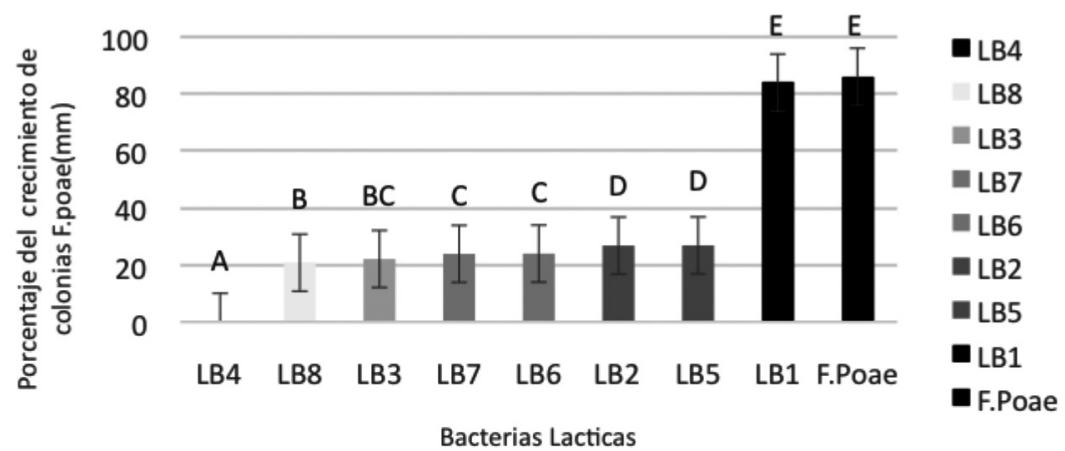

Figura 1. Efecto antagónico de las bacterias lácticas obtenidas de la miel de T. angustula contra F. poae.

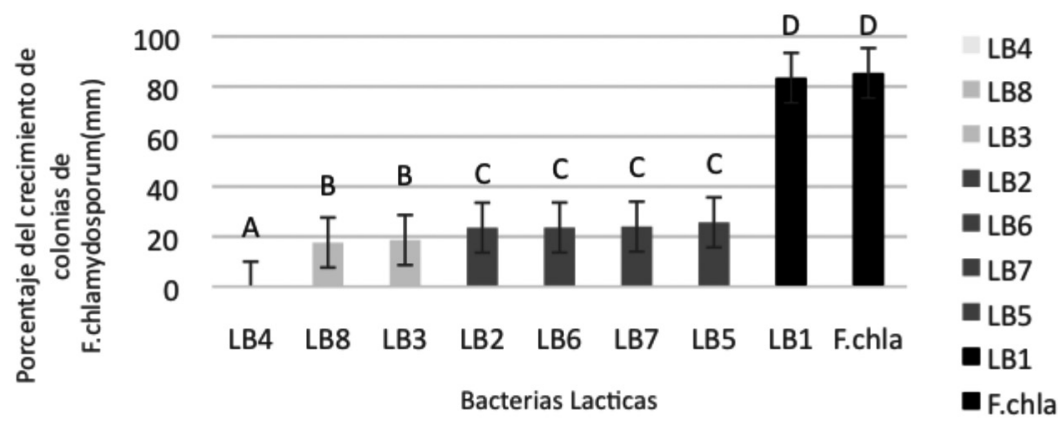

Figura 2. Efecto antagónico de bacterias lácticas provenientes de la miel de T. angustula frente a F. chlamydosporium. 
2018), dependiendo de la variabilidad de la bacteria y las concentraciones de micotoxinas que tuvieron los hongos (Franco et al., 2011).

El comportamiento producido por la bacteria LB4 se relacionó con lo expuesto por Luz et al., 2020, quienes señalaron que algunas bacterias lácticas generaron biocomplejos con una variedad de metabolitos como proteínas, péptidos, y ácidos orgánicos, que actuaron como compuestos antimicóticos. Esto ocasionaría la inhibición total de los hongos patógenos, por parte de LB4.

\section{Conclusión}

Este estudio demostró el efecto inhibidor de bacterias lácticas provenientes de mieles de Tetragonisca angustula frente a $F$. poae y F. chlamydosporum. La bacteria láctica LB4 generó la inhibición total de ambos hongos y fue seleccionada como un futuro controlador biológico. Por ello se debe continuar con las investigaciones para establecer la interacción con las plantas afectadas por estas especies.

\section{Literatura citada}

Aween, M.M.; Hassan, Z.; Muhialdin, B.J.; Eljamel, Y.A.; AlMabrok, A.S.W.; Lani, M.N.

2012. Antibacterial activity of Lactobacillus acidophilus strains isolated from honey marketed in Malaysia against selected multiple antibiotic resistant (MAR) gram-positive bacteria. J. Food Sci., 77: 364-371.

Bartkiene, E.; Bartkevics, V.; Lele, V.; Pugajeva, I.; Zavistanaviciute, P.; Mickiene, R.; Zadeike, D.; Juodeikiene, G. 2018. A concepto of mould spoilage prevention and acryla mide reduction in wheat bread: Application of lactobacilli in combination with a cranberry coating. Food Control, 91: 284-293.

Carrillo, L.; Gómez Molina, S.E.; Benítez Ahrendts. M.R. 2001. Especies de Fusarium Toxicogénicas en sorgo de grano. Boletín Micológico, 16: 15-18.

Cortopassi Laurino, M.; Imperatriz Fonseca; V.L.; Roubik;

D.W.; Dollin, A.

2006. Heard T et al. Global meliponiculture: challenges and opportunities. Apidologie, 37: 275-292.

Franco, T.S.; García, S.; Hirooka, E.Y.; Ono, Y.S.; Dos Santos, J.S. 2011. Lactic acid bacteria in the inhibition of Fusarium graminearum and deoxynivalenol detoxification. J. Appl Microbiol, 111: 739-748.

Kandler, O.; Weiss, N.

1994. Regular Nonsporing GramPositive Rods. In: Bergey’s Manual of Systematic Bacteriology. $9^{\text {na }}$ Ed. The Williams and Wilkins C. Baltimore. 209-1234.

Luz, C.; Izzo, L.; Ritieni, A.; Mañes, J.; Meca, G.

2020. Antifungal and antimycotoxigenic activity of hydrolyzed goat whey on Penicillium spp: An application as biopreservation agent in pita bread. LWT, 118: 108717.

Palmero, D.; Cara de M.; Iglesias C.; Santos M.; Diezma F.;

Lomas. T.; Tello. J.C.

2008. Evaluación del poder patógeno de especies de Fusarium aisladas de aguas de cauces fluviales y fondos marinos de España sobre cuatro especies vegetales. Bol. San Ver. Plagas, 34: 399-414.

Pekkarinen, A.I.; Sarlin, T.H.; Laitila A.T.; Haikara, A.I.; Jones, B.L.

2003. Fusarium species synthesize alkaline proteinases in infested barley. J. Cereal Sci., 37: 349-356.

Quinto, E.J.; Jiménez, P.; Caro, I.; Tejero, J.; Mateo, J.; Girbes, T. 2014. Probiotic lactic acid bacteria: a review. Food Nutr Sci 5, 1765-1775.

Ramos, O.Y.; Basualdo, M.; Libonatti, C.; Vega, M.C.

2019. Current status and application of lactic acid bacteria in animal production systems with a focus on bacteria from honey bee colonies. Journal of Applied Microbiology, 128: 1248-1260.

Schillinger, U.; Villarreal, J.V.

2010. Inhibition of Penicillium nordicum in MRS medium by lactic acid bacteria isolated from foods. Food Control, 21: 107-111.

Schwarz, P.B.

2003. Impact of Fusarium head blight on malting and brewing quality of barley. In Leonard, K.J., Bushnell, W.R. (Eds.). Fusarium. Head Blight of Wheat and Barley. American Phytopathological Society Press. St. Paul, MN, USA. Pp. 395-419.

Stenglein, S.A.

2009. Fusarium poae: a pathogen that needs more attention. J. Plant Pathol. 91: 25-36.

Yáñez-Ordóñez, O.; Trujano Ortega, M., Llorente Bousquets; J. 2008. Patrones de distribución de las especies de la tribu meliponini (Hymenoptera: Apoidea: Apidae) en México. Interciencia, 33: 41-45.

Zamora, L.G.; Beukelman, C.J.; Van den Berg; A.J.; Aerts, P.C.; Quarles Van Ufford, H.C.

2017. An insight into the antibiofilm properties of Costa Rican stingless bee honeys. J. Wound Care, 26: 168-177. 